Published in final edited form as:

J Am Chem Soc. 2019 December 11; 141(49): 19379-19388. doi:10.1021/jacs.9b09812.

\title{
Ultrafast Oxime Formation Enables Efficient Fluorescence Light- up Measurement of DNA Base Excision
}

\author{
David L. Wilson, Eric T. Kool \\ Department of Chemistry, Stanford Cancer Institute and ChEM-H Institute, Stanford University, \\ Stanford, California 94305, United States
}

\begin{abstract}
DNA glycosylases constitute a biologically and biomedically important group of DNA repair enzymes responsible for initiating base excision repair (BER). Measuring their activities can be useful for studying the mechanisms DNA damage and repair and for practical applications in cancer diagnosis and drug screening. Previous fluorescence methods for assaying DNA glycosylases are often complex and/or limited in scope to a single enzyme type. Here we report a universal base excision reporter (UBER) fluorescence probe design that implements an unprecedentedly rapid oxime reaction (>150 $\mathrm{M}^{-1} \mathrm{~s}^{-1}$ ) with high specificity for the abasic (AP) site of DNA. The molecular rotor design achieves a robust $>250-500$-fold increase in fluorescence upon reaction with AP sites in DNA. By using the fluorescence reporter in concert with specific DNA lesion-containing substrates, the UBER probe can be used in a coupled assay in principle with any DNA glycosylase. We demonstrate the utility of the UBER probe by assaying five different glycosylases in real time as well as profiling glycosylase activity in cell lysates. We anticipate that the UBER probe will be of considerable utility to researchers studying DNA repair biology owing to its high level of generalizability, ease of use, and compatibility with biologically derived samples.
\end{abstract}

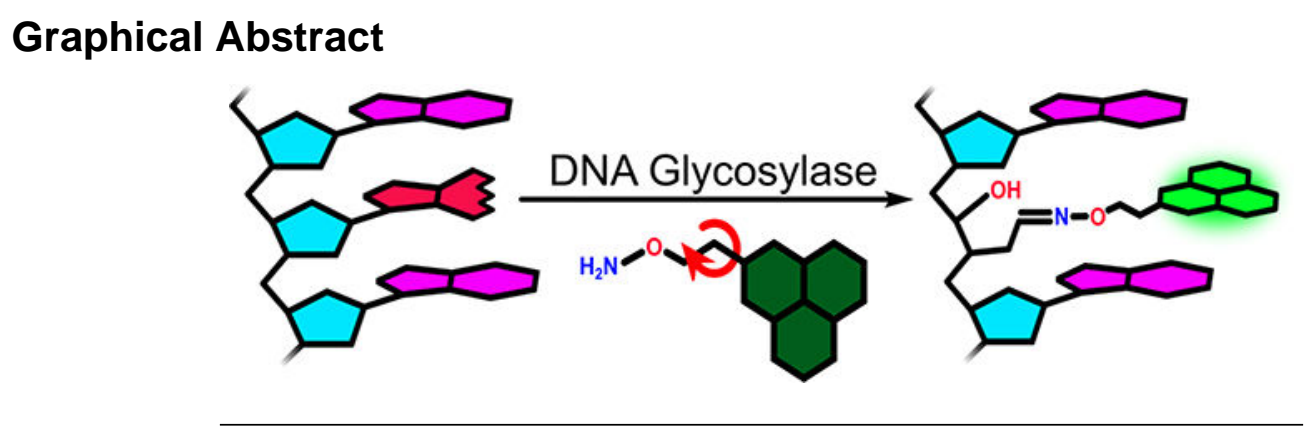

*Corresponding Author: kool@stanford.edu.

The authors declare no competing financial interest.

ASSOCIATED CONTENT

Supporting Information

The Supporting Information is available free of charge at https://pubs.acs.org/doi/10.1021/jacs.9b09812.

Experimental methods, probe synthesis, oligo MALDI spectra, probe excitation/emission spectra, kinetics data, supplementary

fluorescence time courses, molecular modeling, $t_{\mathrm{ss}}$ derivation, and NMR spectra (PDF) 


\section{INTRODUCTION}

The study of the mechanisms of DNA damage and repair is critically important to understanding the origins of cancer. ${ }^{1,2}$ DNA glycosylases are a class of DNA repair enzyme responsible for initiating base excision repair (BER). ${ }^{3-6}$ Enzymes of this broad class recognize damaged or mispaired DNA bases and hydrolyze the $\mathrm{N}$-glyosidic bond between the targeted base and the sugar (Figure 1). The resulting hemiacetal abasic (AP) site created by base excision is then cleaved and ultimately filled in by downstream repair enzymes using the complementary strand to preserve the original genetic information. Most glycosylases play a genoprotective role, preventing the accumulation of cytotoxic mutations in the genome. ${ }^{2}$ For example, two important human glycosylases are OGG1 $1,{ }^{7,8}$ which excises 8-oxoguanine, one of the most common oxidized lesions in DNA, ${ }^{2}$ and $\mathrm{UNG},{ }^{9}$ which removes uracil arising from cytosine deamination. Because these forms of damage lead to mutations, DNA glycosylases such as OGG1 have been extensively investigated for their role in oncogenesis. ${ }^{10}$ Many cancers are characterized specifically by aberrant DNA glycosylase activity; one example is found in MUTYH-associated polyposis (MAP), ${ }^{11}$ a disease that often progresses to colon cancer and is characterized by low MUTYH activity. Conversely, upregulation of glycosylases is also known to confer chemotherapy resistance by increased DNA repair. ${ }^{12}$ In light of the success of PARP inhibitors, which are employed to downregulate DNA repair in breast cancer patients, DNA glycosylases have also become a topic of interest as potential targets for cancer treatment. ${ }^{13}$ In addition to genoprotection, researchers are also studying other roles that DNA glycosylases play in areas such as immune responses and epigenetics. For example, OGG1 has been shown to play a role in allergen-mediated inflammatory responses, ${ }^{14}$ and TDG, another DNA glycosylase, is now well established as a regulator of DNA epigenetic marks. ${ }^{15}$

Given their central roles in cancer biology and their potential therapeutic impact, DNA glycosylases have become a target for development of probes to measure their activities. ${ }^{16}$ Conventional biochemical assays of DNA glycosylase activity require discontinuous, gelbased, or radiation release assays, which are poorly suited to high throughput screens or assaying activity in biological contexts. Such limitations have stimulated recent efforts toward developing fluorescence sensors of DNA glycosylases. Fluorescence assays have the advantage of being real-time, sensitive, and potentially adapted for studies in cells or lysates, and the measurements are readily accessible to most researchers through microplate readers or epifluorescence microscopy. However, the vast majority of reported fluorescence probes of DNA glycosylases either require multiple components or discontinuous steps to generate a fluorescence signal, thereby negating the real-time advantage of fluorescence and/or prohibiting their use in complex media. ${ }^{16}$ Multicomponent glycosylase sensors, such as those relying on DNA cleavage, require multistep transduction pathways to generate a fluorescence signal, creating multiple avenues for false negatives or positives. Other reported sensor designs have used highly modified oligonucleotide substrates. ${ }^{17}$ Probes based on modified oligonucleotides can potentially alter enzyme/substrate interactions and may be challenging to produce for researchers unfamiliar with phosphoramidite chemistry and/or automated oligonucleotide synthesis. Finally, most reported glycosylase reporters are limited to a specific DNA glycosylase, a fact that has given rise to a patchwork of probes and assays, 
leaving researchers with no single, easy-to-use tool. In an effort to meet these challenges, we sought to develop a universal base excision reporter (UBER) probe design that could enable measurements of any glycosylase using a single small-molecule reporter.

The UBER probe design was inspired by several recently reported twisted internal charge transfer (TICT) and molecular rotor probes. ${ }^{18,19}$ In both TICT and rotor probes, a fluorophore that experiences nonradiative relaxation through bond rotation is conjugated to a reactive functionality that targets the probe to a biomolecule of interest. The probe is designed such that upon binding the target biomolecule, bond rotation within the probe becomes constrained, resulting in a significant fluorescence increase. Many of the recently reported probes are targeted to hydrophobic protein pockets such as the active site of the Halotag enzyme. ${ }^{19,20}$ The AP site generated in DNA by base excision potentially constitutes a similarly constrained, water-excluded target site, which we hypothesized could be exploited to constrain a TICT or rotor-based probe (Figure 1). The hemiacetal AP site is in equilibrium with its aldehyde form, which provides a convenient handle that can be targeted with reactive alpha nucleophiles. Previously reported aldehyde reactive probes (ARP) have applied this chemistry to label AP sites with aminooxy-functionalized fluorophores and affinity tags: ${ }^{21-24}$ however, none have attempted to use such chemistry to engender a fluorogenic or light-up response. As a result, use of such molecules has been limited to AP site quantitation by gel-based assays rather than real-time base excision monitoring. By simultaneous labeling of the AP site and activation of probe fluorescence, the UBER probe design can in principle report in real-time on base excision activity. Furthermore, by employing the probe with substrates containing a variety of DNA lesions, the UBER probe might be used to measure any potential glycosylase or substrate of interest.

Herein we describe the design and synthesis of aminooxy-functionalized, fluorescence lightup probes that undergo ultrafast oxime formation to measure DNA base excision in realtime. The molecular rotor-based design reacts with high specificity toward the AP site of DNA at an unprecedented rate $\left(\sim 150-300 \mathrm{M}^{-1} \mathrm{~s}^{-1}\right)$ and affording a $\sim 250-500$-fold fluorescence light-up response. The coupled UBER probe assay enables facile quantification of specific glycosylase activities in vitro or in cell lysates. To test the ease of use and utility of the UBER probe, we measured the activities of UNG and OGG1 in cell lysates representing DNA glycosylases with both high and low turnover numbers, respectively.

\section{RESULTS AND DISCUSSION}

\section{Probe Design and Synthesis}

To begin our study, we synthesized aldehyde-reactive linker $\mathbf{L} 1$ and the N-methylated $\mathbf{L 4}$ using previously reported chemistry 25 (Figure 2a). The aminooxy alpha nucleophile was selected because the resulting oxime bond is less readily reversible than hydrazine/ hydrazone adducts, ${ }^{26}$ and oximes have previously proven useful to label DNA AP sites. ${ }^{21}$ We attached linkers $\mathbf{L} \mathbf{1}$ and $\mathbf{L} \mathbf{4}$ to three fluorophores that have been previously reported as TICT probes or molecular rotors. Specifically, we chose the well characterized environmentally sensitive 1,8 -naphthalimide fluorophore, ${ }^{27}$ the molecular rotor 9-(2carboxy-2-cyanovinyl)-julolidine (CCVJ) ${ }^{18}$ and the environmentally sensitive benzoxadiazole dye ${ }^{28}$ yielding probes $\mathrm{NP} 1, \mathrm{CCVJ} 1$, and BD1 respectively. In addition to 
their reported environmental sensitivity, we selected these fluorophores for their spectral range as well as synthetic ease of conjugation (see Supporting Information (SI) for full synthesis details).

\section{Fluorescence Responses}

To assess the potential fluorescence response of each probe, we prepared a 17mer DNA hairpin containing a single AP site and reacted it with a 10-fold excess of probe overnight (see SI for full procedure). The subsequent DNA-probe conjugates were precipitated to remove excess fluorophore, and full DNA labeling was confirmed by MALDI-TOF mass spectrometry (Table S2). The reacted DNAs were resuspended in buffer to a concentration of $2 \mu \mathrm{M}$ and the emission spectra compared with the spectra of the free probes in solution. We found that in comparison to the free dye, all three probes demonstrated increased fluorescence when covalently attached to the DNA AP site (Figure 2b). In particular we were pleased to see that CCVJ1 yielded a dramatic 256-fold increase in fluorescence when bound to the AP site. In addition to its large fluorescence response, CCVJ1 is accessed readily through a facile four-step synthesis and has good spectral overlap with fluorescein. This makes the probe accessible to a wide range of researchers and well suited to the majority of fluorescence-based instruments.

Because the probes based on 1,8-naphthalimide and benzoxadiazole had multiple potential linker attachment sites, we also synthesized NP2 and BD2 with altered attachment points and found that in the case of $\mathrm{BD} 2$, changing the position of the linker yielded a much lower increase in fluorescence over the free probe. This was somewhat surprising given that the attachment site is closer to the bond that is hypothesized to induce TICT. ${ }^{27}$ While NP2 demonstrated similar photophysical properties to NP1, the synthesis and purification of NP2 was simpler, making it the preferred 1,8-naphthalimide-based probe. Due to the close overlap in excitation spectra of all three probe designs, they can easily be excited at a common wavelength ( $440-480 \mathrm{~nm})$ and produce a multicolor output for multiplexing applications if desired (Figure S1).

\section{Oxime Formation Kinetics}

After determining that CCVJ1 produced the strongest fluorescence light-up signal of the compounds tested, we next evaluated reaction rates with this probe. To measure oxime formation kinetics, $5 \mu \mathrm{M}$ CCVJ1 was reacted with $20 \mu \mathrm{M}$ AP DNA, and the resulting fluorescence time course was used to determine second-order rate constants by nonlinear regression analysis. We selected Tris buffer because it is commonly used in glycosylase assays with a salt concentration of $100 \mathrm{mM} \mathrm{NaCl}$. To our surprise, we found that probe CCVJ1 demonstrated remarkably rapid oxime formation kinetics (Figure 3a). At pH 7.0, CCVJ1 reacted with an apparent second-order rate constant of $147 \mathrm{M}^{-1} \mathrm{~s}^{-1}$ (Table 1), $10^{3}$ $10^{4}$ times faster than typical oxime formation in neutral aqueous buffer. ${ }^{26}$ These results are important because rapid oxime formation are crucial for an efficient coupled assay (see below). Consistent with previous studies of oxime kinetics, ${ }^{26}$ we found that second-order rate constants decreased with increasing $\mathrm{pH}$. 
We performed additional experiments to study the origins of this unusually rapid reaction. A study by Kojima et al. ${ }^{29}$ demonstrated that a naphthalene moiety in close proximity to an aminooxy group accelerated the rate of oxime formation with double stranded AP DNA 3fold over a probe with a longer linear linker. The authors suggested that the planar naphthalene accelerates oxime formation by prebinding the DNA through stacking interactions. The maximum rate observed in their study, however, was $\sim 0.005 \mathrm{M}^{-1} \mathrm{~s}^{-1}$ at $\mathrm{pH}$ 8 , over 5000 times slower than the $k_{2}$ we observed with CCVJ1 at pH 8 (Table 1). To test the effect that proximity between the alkoxyamine and planar portion of the probe had on oxime kinetics in our probes, we synthesized probes having variable-length linkers (CCVJ2 and CCVJ3) from aldehyde reactive linkers $\mathbf{L} 2$ and $\mathbf{L 3}$, respectively (Figure 2a). We found that homologating the linker length of CCVJ1 by one or two ethylene glycol units slowed the reaction rate considerably (Figure $3 b$ ), which is consistent with the notion that the hypothetically prebound aryl group in CCVJ1 positions the nucleophile well for reaction, while longer linkers in $\mathrm{CCVJ} 2 / 3$ would engender a higher entropic penalty for reaction. When linker L1 (having no aryl group) was added to the reaction as a competing alpha nucleophile, it showed no effect at concentrations up to $500 \mu \mathrm{M}$, suggesting that the presence of the aryl group in CCVJ1 markedly accelerates the reactivity of linker L1 (Figure S3). Interestingly, the brightness of CCVJ2 and CCVJ3 probes was significantly diminished compared to that of CCVJ1, likely owing to greater conformational freedom of the longer linkers in the bound state (Figure S4). To test the importance of a double-stranded DNA structure to the rate and fluorescence response, we reacted an AP-containing single-stranded DNA oligonucleotide with CCVJ1. At $\mathrm{pH} 7, \mathrm{CCVJ} 1$ reacted with a second-order rate constant of $33 \mathrm{M}^{-1} \mathrm{~s}^{-1}$ with the single-stranded substrate, roughly 5-fold slower than a double-stranded hairpin with identical sequence context (Figure S5). Furthermore, the reaction with the single-stranded DNA only yielded a 4-fold increase in fluorescence, suggesting that rigidly stacked neighboring bases (as found in double-stranded DNA) are key to constraining bond rotation in CCVJ1. These results are consistent with the hypothesis that the more rigid binding site created by the AP site in double stranded DNA is essential to the observed rate acceleration.

In addition to Tris buffer, we also measured oxime formation kinetics of CCVJ1 with AP DNA in a solution of a catalytic amine buffer previously shown to accelerate oxime

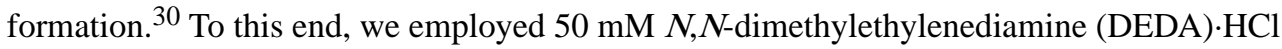
buffered to a $\mathrm{pH}$ of 7.0 in place of the above Tris buffers. Under these conditions, we found that the rate of oxime formation proceeded yet $\sim 3$ times faster, achieving a second-order rate constant of $440 \mathrm{M}^{-1} \mathrm{~s}^{-1}$ (Figure 3b). Such rapid rates of oxime formation at neutral $\mathrm{pH}$ are unprecedented for unactivated aldehydes.

To further explore the hypothesis that the oxime rate acceleration in these AP-site DNAs was related to base stacking interactions, we measured the fluorescence of CCVJ1 in the presence and absence of a non-lesion-containing DNA hairpin. We observed a 2.5 -fold increase in fluorescence intensity upon addition of DNA to the probe, suggesting a small but significant amount of intercalation (Figure S6). When we instead used a DNA hairpin containing a tetrahydrofuran spacer (a pseudo AP site), which mimics an AP site without the reactive hemiacetal, we observed a $\sim 10$-fold increase in fluorescence over the free probe, $\sim 4$ - 
fold higher than with undamaged DNA, suggesting that the probe intercalates more readily into the AP site mimic than into duplex DNA alone (Figure S6). Without a covalent attachment to the AP site, the dye-DNA interaction is hypothesized to be dynamic and flexible, given the relatively low fluorescence increase compared to the 256-fold enhancement observed upon covalent attachment after reaction with an AP site. In a separate experiment, we tested the effect of adding an equimolar amount of pseudo AP DNA to the reaction with a true abasic site DNA and observed no effect on the rate of apparent oxime formation (Figure S6).

\section{Neighboring Base Effect}

Given the well-characterized ability of DNA nucleobases to quench fluorescent species, ${ }^{31}$ we sought to explore the effect that neighboring bases $\mathbf{X}$ and $\mathbf{Y}$ had on the potential light-up signal of CCVJ1 as well as on the rate of oxime formation (Figure 4a,b). To test this, we reacted CCVJ1 with a library of 16 DNA hairpins representing all possible combinations of neighboring DNA bases (Figure 4a,b). We found that cytosine and guanine exert the least quenching effect, with combinations of $\mathbf{X}=\mathrm{C} / \mathrm{G}$ and $\mathbf{Y}=\mathrm{C} / \mathrm{G}$ yielding the greatest maximum signals, while adenine and thymine exert an apparent quenching effect that reduced signal by half. With respect to the rate of oxime formation, the greatest effect appears to be exerted by the $3^{\prime}$ neighboring base $\mathbf{Y}$. Both guanine and adenine $3^{\prime}$ to the AP site consistently yielded the fastest oxime formation, with $\mathbf{X}=\mathrm{A}, \mathbf{Y}=$ A yielding the fastest rate (relative rate $=1.0$ ), while combinations with thymine or cytosine yielded rates about half as fast. In general, purine neighboring bases gave the highest rates, consistent with the apparent need for preassociation and stacking of the probe with the DNA to increase local concentration of the reactive aminooxy group. Purines are documented to stack more strongly with aromatic species than pyrimidines. ${ }^{32}$

In addition to the $5^{\prime}$ and $3^{\prime}$ neighboring bases, we were also interested in studying the effect of the orphaned base $\mathbf{Z}$ paired opposite the abasic site on the UBER probe system (Figure $4 \mathrm{c}, \mathrm{d}$ ). Using the sequence where $\mathbf{X}=\mathrm{C}$ and $\mathbf{Y}=\mathrm{G}$, we varied the identity of the base $\mathbf{Z}$ opposite the AP site. We found that pyrimidine bases afforded the greatest fluorescence response, increasing the overall signal by almost 50\% compared to cases when $\mathbf{Z}$ is a purine (Figure 4c). Given that neighboring pyrimidines were shown to be quenchers of CCVJ1, the strong fluorescence signal observed when $\mathbf{Z}=\mathrm{C}$ and $\mathbf{Z}=\mathrm{T}$ suggests that steric occlusion by the orphaned base plays a greater role in the degree of probe light up than any electronic interactions. As a result, the smaller pyrimidine bases yielded a greater fluorescence light-up response than the larger purine bases. We also observed a strong effect by the opposing base on the rate of oxime formation (Figure 4d). Adenine, which has the strongest base stacking interactions, ${ }^{32}$ resulted in the slowest rate of oxime formation. Conversely, cytosine, which has the weakest base stacking interactions showed the fastest rate of oxime formation. This trend is in contrast to the neighboring base effect discussed above in which stronger stacking bases accelerated the rate of oxime formation. Together these results suggest that the rate of oxime formation is mediated by the favorability of CCVJ1 stacking with adjacent $\mathbf{X}$ and $\mathbf{Y}$ bases as well as the competition with base stacking of the opposing $\mathbf{Z}$ base. Overall, we conclude that the optimal neighboring base combination for monitoring glycosylase activity with CCVJ1 can be attained with $\mathbf{X}=\mathrm{C}, \mathbf{Y}=\mathrm{G}$, and $\mathbf{Z}=\mathrm{C}$ which reacted with CCVJ1 at a 
rate of $320 \pm 13 \mathrm{M}^{-1} \mathrm{~s}^{-1}$ and afforded an overall 508 -fold increase in fluorescence relative to the probe alone (Figure S13).

Using the experimental data obtained by our neighboring base studies, we constructed a model of CCVJ1 bound to the AP site (Figures 4e,f and S15). The resulting structure shows that the dye intercalated into the AP site and suggests that CCVJ1 may approach the AP site from the major groove with substantial overlap to the $3^{\prime}$ side of the dye, consistent with the fact that the $3^{\prime}$ neighboring base exerts the most significant effect on rate. The model suggests that the aromatic ring of CCVJ1 plausibly undergoes stacking with neighboring bases, consistent with the observed fluorescence quenching effect, while the linker protrudes into the minor groove. Additionally, the orphaned thymidine base is partially disrupted from its base stacking interactions.

\section{AP Site Selectivity and Preference}

One potential limitation to the aldehyde-reactive probe design in its current implementation is the potential for other aldehydes or ketones in the environment to react with the probe and generate a false positive signal. Because our probe design depends on conformational restriction to induce a light-up signal, we hypothesized that off-target oxime formation with small molecules might induce a relatively small signal relative to DNA, thus providing a measure of selectivity in signaling. To test this possibility, we reacted CCVJ1 with $500 \mu \mathrm{M}$ of several biologically relevant ketones and aldehydes including formaldehyde, 4hydroxybenzaldehyde, pyridoxal phosphate, glyoxylic acid, pyruvic acid, and $a$-keto glutarate and found that none of them generated a significant light-up response after $30 \mathrm{~min}$ of incubation, suggesting that the light-up response of this probe is highly selective for the DNA AP site (Figure S7). Another potential concern is that ketones or aldehydes in the environment might compete with the DNA AP site to react with the aminooxy group, thereby consuming the free probe and reducing the maximum signal. Given the rapid oxime formation kinetics observed between our probes and the AP site in DNA, we were hopeful that side reactions with other carbonyl compounds would proceed relatively slowly, giving the probe a high degree of kinetic selectivity for its intended DNA target. We initially tested the reactivity of CCVJ1 with AP site-containing DNA in the presence of increasing amounts of competing 2-deoxyribose, the closest small-molecule analogue to the DNA AP site. We found that even in the presence of $1 \mathrm{mM}$ deoxyribose (200 equiv), there was no effect on the maximum signal observed from the probe, and at $4 \mathrm{mM}$ ( 800 equiv) the probe still retained $85 \%$ of the signal compared to the AP DNA alone (Figure 5). We repeated this experiment with pyruvic acid, a highly reactive ketone and a common cellular metabolite. We found that concentrations up to $200 \mu \mathrm{M}$ pyruvate (40 equiv), which is comparable to levels of pyruvate found in the cell, ${ }^{33}$ gave no significant reduction in overall signal. These data further bolster the hypothesis that there is a preassociation between the DNA bases surrounding the AP site and the planar portion of the probe, causing the rate acceleration to be highly selective for the AP site of DNA. 


\section{Coupled Assay Measurements}

Similar to an enzyme-coupled assays, the UBER probe design generates signal via a secondary reaction which consumes the product of the first enzymatic reaction according to the following scheme:.

$$
S \stackrel{v_{0}}{\rightarrow} \stackrel{v_{1}}{\rightarrow} P
$$

The observed signal, therefore, is equal to the rate $v_{1}$. However, unlike enzyme-coupled assays, the UBER probe design does not require enzymatic catalysis for the secondary reaction to occur at a reasonable rate. In the early phase of enzyme-coupled reactions, as intermediate accumulates, the rate of $v_{1}$ increases and asymptotically approaches $v_{0}$. This relationship allows for the direct measurement of enzyme activity in a coupled assay system. The delay between the start of the reaction $(t=0)$ and the time at which $v_{0} \approx v_{1}$ is referred to as the lag time, $t_{\mathrm{ss}}$. For a one-enzyme-coupled system, $\mathrm{McClure}^{34}$ derived the equation for lag time which can be adapted for our system as

$$
t_{\mathrm{ss}}=\frac{\ln (1-F)}{k_{2} \times[\text { probe }]}
$$

where $k_{2}$ is the second-order rate constant of oxime formation, [probe] is the concentration of UBER probe, and F1 is a constant term defining the limit at which $v_{0}$ and $v_{1}$ are defined as equal, typically 0.99 (see SI for full derivation). eq 1 demonstrates that the lag time for the UBER probe-coupled assay is governed solely by the concentration of probe and the second-order rate constant of oxime formation. Therefore, we can adjust assay conditions to ensure that lag time is reasonably short by increasing probe concentration.

Given the second-order rate constants calculated above for CCVJ1 in Tris buffer and a probe concentration on the order of $10-100 \mu \mathrm{M}$, we can calculate that $t_{\mathrm{ss}}$ for an UBER probecoupled assay will be on the order of 5-50 min. This is in marked contrast with typical oxime $k_{2}$ rate contants of $0.01-1 \mathrm{M}^{-1} \mathrm{~s}^{-1}$ which would yield impractical $t_{\mathrm{ss}}$ values of $10-$ $1000 \mathrm{~h}$ unless $\mathrm{mM}$ concentrations of probe were used. Therefore, the ultrafast oxime formation kinetics of the UBER probe are essential for the practical implementation of a coupled assay and enable the direct measurement of enzyme activities.

\section{CCVJ1 as a General DNA Glycosylase Sensor}

On the basis of the results of our neighboring base effect study, we purchased or prepared several glycosylase oligonucleotide substrates in which the identity of the base lesion $\mathbf{X}$ was varied to correspond to the known activities of different target glycosylases (Figure 6e). For these studies we chose human enzymes SMUG1/UNG, OGG1, MPG, and NTH1, which represent a diverse array of human glycosylases. We set the standard assay conditions as 2 $\mu \mathrm{M}$ substrate and $20 \mu \mathrm{M}$ probe. Assays were carried out in a $60 \mu \mathrm{L}$ volume in a 384-well format on a microplate reader using a fluorescein filter set. For each enzyme, we were able to observe a robust fluorescence signal (Figures 6a-d). Consistent with literature 
measurements, we found SMUG1 to be significantly slower than UNG on a double stranded substrate $^{9}$ (Figure 6a).

One practical issue with the UBER probe design is the secondary lyase activity of the subset of BER enzymes that act as bifunctional glycosylases. While monofunctional glycosylases only exhibit base excision activity, bifunctional glycosylases possess a secondary strand scission or lyase activity that cleaves the DNA backbone after base excision. Because alpha nucleophiles such as alkoxyamines are known to inhibit lyase activity and prevent cleavage of the AP site, ${ }^{23,35}$ we hypothesized that the UBER probe system could still detect bifunctional glycosylases. While lyase activity is common in bacterial glycosylases, among human glycosylases only NTH1 and NEIL1-3 possess robust lyase activity. ${ }^{3}$ We note that while OGG1 is considered a bifunctional glycosylase, its lyase activity proceeds relatively slowly and is generally considered a monofunctional glycosylase in vivo. ${ }^{36}$ Indeed, under our assay conditions, OGG1 generated signal in an equivalent manner to the monofunctional glycosylases we tested. However, when testing CCVJ1 with NTH1 using a 5hydroxycytosine $(5 \mathrm{hC})$-containing DNA hairpin, we observed a partial lowering of signal compared to the monofunctional glycosylases, suggesting that some of the hairpin substrate is cleaved prior to reacting with CCVJ1. In some contexts, NTH1 is reported to behave as a pseudo-single-turnover enzyme which could also explain the partial loss of signal. ${ }^{37}$ However, subsequent additions of enzyme did not yield a fluorescence increase which rules out the pseudo-single-turnover explanation (Figure S14). We found that using higher concentrations of the DNA substrate $(60 \mu \mathrm{M})$ yielded higher fluorescence signal, consistent with the hypothesis that many of the potential AP-sites are lost to lyase activity. Despite this loss of signal, the overall fold change observed (20-fold) is still sufficient for detection and quantification of enzymatic activity.

To test the utility of the probe-coupled assay for characterizing inhibitors, we measured the $\mathrm{IC}_{50}$ value of the UNG inhibitor UGI (Figure $6 \mathrm{f}, \mathrm{g}$ ). The resulting $\mathrm{IC}_{50}$ of $7.53 \pm 0.44 \mathrm{nM}$ is consistent with literature values reporting its tight $1: 1$ binding stoichiometry. ${ }^{38,39}$ In all cases, the $z$-factor of the assay was calculated to be $>0.95$, well above the threshold necessary for high throughput screening.

\section{Assaying Substrates Generated in Situ}

Because the probe and substrate are independent from one another, the UBER probe assay can also be implemented without synthesizing lesion-containing oligonucleotide substrates. This is particularly advantageous for cases where the DNA lesion of interest is costly or challenging to incorporate into a synthetic oligonucleotide using conventional phosphoramidite synthesis. For example, by treating calf thymus DNA (ctDNA) with increasing concentrations of the DNA alkylating compound dimethyl sulfate (DMS) for $2 \mathrm{~h}$, we were able to generate a suitable alkylated DNA substrate for the enzyme MPG (Figure 7). Upon treatment of $0.1 \mathrm{mg} / \mathrm{mL}$ alkylated ctDNA with $100 \mathrm{nM}$ MPG in the presence of CCVJ1 $(20 \mu \mathrm{M})$, we observed an increase in fluorescence that correlated linearly to the concentration of DMS used (Figure S8a). Importantly, alkylated ctDNA that was treated with the highest level of DMS (1 mM) showed no increase in fluorescence when treated with probe alone, suggesting that spontaneous depurination of the alkylated ctDNA, which could 
lead to a false positive, occurs at a negligible rate under our assay conditions (Figure 7). Preincubation of the alkylated ctDNA with CCVJ1 prior to the addition of MPG also showed stable fluorescence, providing further evidence that spontaneous depurination occurs at a rate far below background (Figure S8c). We were similarly able to produce a substrate for OGG1 by treating calf thymus DNA under oxidizing conditions with Fenton's reagent (Figure S8b). These preliminary tests suggest that by generating suitable enzyme substrates in situ, the UBER probe can be employed with inexpensively produced, biologically derived substrates and can circumvent the need to synthesize modified oligonucleotides if desired.

\section{Profiling Cellular Glycosylase Activity}

After demonstrating that the UBER probe could efficiently report on base excision activity from a variety of glycosylases in vitro, we explored whether the probe could be employed to profile endogenous glycosylase activity in cell lysates. We first tested the UBER probe's ability to report on UNG activity in whole cell lysates using the previously described UNG hairpin substrate (Figure 8a). Using $5 \mu \mathrm{M}$ hairpin and $25 \mu \mathrm{M} \mathrm{CCVJ1}$, we observed a strong, real-time fluorescence response in the presence of $0.2 \mathrm{mg} / \mathrm{mL}$ crude HeLa cell lysate. The oligonucleotide substrate sequence is based on the high melting GAA sequence motif that has been shown to confer high nuclease stability in short hairpins. ${ }^{40}$ To confirm that the fluorescence response originated from endogenous UNG activity and not off-target binding with proteins or spontaneous depurination, we treated lysate with CCVJ1 and a control hairpin in which the lesion had been replaced by an undamaged T:A base pair. Importantly, the control hairpin yielded no fluorescence response, indicating a low degree of false positive signal. Additionally, treating the lysate with $1 \mathrm{U} / \mathrm{mL}$ of inhibitor UGI completely ablated the fluorescence response, confirming the specific enzymatic origin of the light-up activity. To our knowledge, CCVJ1 represents the first fluorogenic probe to measure realtime UNG activity in cell lysates.

To further demonstrate the utility of the UBER probe, we used it to monitor changes in UNG activity at different phases of the cell cycle. Lysates were generated from HeLa cells arrested in the G0/G1 phase as well as actively dividing cells, and UNG activity was quantified by measuring initial rate velocity. We observed a $\sim 5$-fold increase in UNG activity in actively dividing cells relative to cells arrested in the G0/G1 phase (Figure 8b), consistent with literature reports. ${ }^{41}$ This experiment demonstrates the ability of the UBER probe to measure dynamic changes in glycosylase expression level in response to environmental stimuli or disease states using a simple mix-and-measure format.

Encouraged by the results, we then tested whether the UBER probe could detect endogenous glycosylase activity from a more challenging target such as OGG1. It is well established that the turnover number of UNG is quite high $\left(\sim 1-10 \mathrm{~s}^{-1}\right)^{5}$ while the turnover number for many other glycosylases is quite low $\left(0.001-0.1 \mathrm{~s}^{-1}\right) .{ }^{42}$ Additionally, most glycosylases, including OGG1, have very low basal expression levels in healthy cells. Given these facts, previous attempts to detect OGG1 activity in lysates have relied on a multistep signal amplification process $^{43}$ or extended reaction times ${ }^{44}(24-48 \mathrm{~h}$ ) to yield signal. However, we found that after a $4 \mathrm{~h}$ incubation with CCVJ1, we were able to quantify OGG1 activity in MCF7 lysates (Figure 9). While the overall signal was appreciably lower than that observed for UNG, 
addition of the potent OGG1 inhibitor SU0268 completely abolished OGG1 repair activity relative to the control, demonstrating the sensitivity of CCVJ1. In this case, the majority of the background signal observed was attributed to intercalation of probe into unreacted hairpin as well as genomic DNA. In additional experiments, we also used CCVJ1 to measure OGG1 activity in HeLa cells which demonstrated $\sim 3 \times$ lower OGG1 activity, consistent with literature findings of relative OGG1 activity in these two cell lines ${ }^{45}$ (Figure S9). Interestingly, HeLa cells demonstrated $\sim 2 \times$ higher UNG activity than MCF7 cells (Figure S10).

\section{CONCLUSIONS}

We have shown that molecular rotor dyes with optimized, relatively short linkers can yield robust and rapid fluorescence signals in response to abasic sites generated during DNA base excision repair. Perhaps the most striking finding in this study is the unprecedentedly fast oxime formation reaction observed between UBER probe CCVJ1 and DNA AP-sites. We observe rates that are 3-4 orders of magnitude faster than standard oxime bond formation reactions at neutral $\mathrm{pH}$. As a bioorthogonal labeling strategy, oxime linkages have generally been criticized for suffering from slow reaction rates $\left(\sim 0.001-0.01 \mathrm{M}^{-1} \mathrm{~s}^{-1}\right)$ relative to a number of recently reported biofunctionalization reactions such as tetrazine ligations ( 1$100 \mathrm{M}^{-1} \mathrm{~s}^{-1}$ ). Given this context, the results presented here are all the more surprising. It is worth noting that under more conventional oxime formation rates, the UBER probe design would require days or possibly months to reach $t_{\mathrm{ss}}$ and would likely suffer from off-target reactivity with other aldehydes and ketones. Therefore, the key to the success of the UBER probe design hinges upon its extraordinarily selective and rapid oxime formation with the AP site.

The UBER probe design exhibits several significant advantages over previously reported methods for assaying DNA glycosylase activity. Traditional biochemical methods such as gel-based assays or radiation release assays have the advantage of sensitivity as well as using unmodified, native substrates. ${ }^{46,47}$ However, they are discontinuous and therefore time and labor intensive. To illustrate this point, consider a small 394-compound library screen of potential glycosylase inhibitors. Using a discontinuous method, screening each compound at a single concentration using five time-points to measure $v_{\mathrm{i}}$ would require 1970 individual enzyme reactions to be run and quenched at the same time for each prior to running each reaction on a gel. Using a continuous fluorescence assay, the entire screen could be completed on a single microplate in a matter of hours. Molecular beacon probes of base excision, ${ }^{48}$ like the current probes, have the advantage of being continuous; however, because they rely on strand cleavage they cannot be used with monofunctional glycosylases, which represent the majority of human glycosylases, without further downstream processing. CCVJ1, with its 250-500-fold increase in fluorescence, combines sensitivity and generalizability in a continuous assay that can be adapted for use with virtually any human glycosylase. Furthermore, the ability to monitor the dynamic response of glycosylase activity in cell lysates enables efficient glycosylase activity profiling which previously would have only been achieved through lower sensitivity fluorescence methods which could require days to develop an observable signal. ${ }^{44}$ 
By utilizing a separate reporter molecule, the UBER probe can be paired in a coupled assay with any DNA substrate without further modification. This could enable sensing of as-yet undiscovered DNA glycosylase activities. In many cases, enzyme substrates can be purchased from commercial oligonucleotide suppliers or generated in situ from biologically derived DNA, negating the need to purchase or synthesize heavily modified oligonucleotides. Additionally, by working with native substrates rather than modified reporter oligonucleotides, the UBER probe produces no interference with native enzyme activity. Unlike previous probes that rely on secondary DNA cleavage (lyase) activity to generate signal, the UBER probe generates signal in direct proportion to base excision and requires no secondary enzyme activity. In particular, CCVJ1 produces a significantly larger light-up response than a conventional molecular beacon ${ }^{48}$ which must be customized for each enzyme of interest. This large-fold change enables sensitive detection of DNA glycosylase activity in cell lysates in a relatively short amount of time.

It should be noted that both the naphthalimide probes NP1 and NP2 as well as benzoxadiazole probes $\mathrm{BD} 1$ and $\mathrm{BD} 2$ also experienced accelerated rates of oxime formation and substantial light-up signals with AP DNA (Figure S11), suggesting that this molecular strategy could be general and can provide different emission colors as desired (Figure S1). The best-performing probe studied here was CCVJ1, which employs a molecular rotor dye with a short, two-carbon linker and yields a robust >250-500-fold fluorescence light-up response to AP sites. The probe design enables real-time reporting of glycosylase base excision in a simple mix-and-read format. Additionally, because of its unusual rate acceleration and light-up mechanism, the UBER probe design offers very low background and low off-target light-up signals, even in the presence of high concentrations of common small-molecule carbonyl compounds and the complex matrix of cellular lysates. Moreover, the synthesis of CCVJ1 is facile, proceeding in four steps with high yields. These properties make the probe a promising tool for researchers interested in studying, in principle, any DNA glycosylase either in vitro or in tissue or cell extracts.

\section{Supplementary Material}

Refer to Web version on PubMed Central for supplementary material.

\section{ACKNOWLEDGMENTS}

We thank the U.S. National Cancer Institute (CA217809) for support. D.L.W. acknowledges financial support through an ARCS fellowship.

\section{REFERENCES}

(1). Chatterjee N; Walker GC Mechanisms of DNA Damage, Repair, and Mutagenesis. Environ. Mol. Mutagen 2017, 58 (5), 235-263. [PubMed: 28485537]

(2). Ciccia A; Elledge SJ The DNA Damage Response: Making It Safe to Play with Knives. Mol. Cell 2010, 40 (2), 179-204. [PubMed: 20965415]

(3). Jacobs AL; Schaer P DNA Glycosylases: In DNA Repair and Beyond. Chromosoma 2012, 121 (1), 1-20. [PubMed: 22048164]

(4). David SS; O’Shea VL; Kundu S Base-Excision Repair of Oxidative DNA Damage. Nature 2007, 447 (7147), 941-950. [PubMed: 17581577] 
(5). Krokan HE; Bjørås M Base Excision Repair. Cold Spring Harbor Perspect. Biol 2013, 5 (4), No. a012583.

(6). David SS; Williams SD Chemistry of Glycosylases and Endonucleases Involved in Base-Excision Repair. Chem. Rev 1998, 98 (3), 1221-1262. [PubMed: 11848931]

(7). Lu R; Nash HM; Verdine GL A Mammalian DNA Repair Enzyme That Excises Oxidatively Damaged Guanines Maps to a Locus Frequently Lost in Lung Cancer. Curr. Biol 1997, 7 (6), 397-407. [PubMed: 9197244]

(8). Tchou J; Kasai H; Shibutani S; Chung M; Laval J; Grollman A; Nishimura S 8-Oxoguanine (8Hydroxyguanine) DNA Glycosylase and Its Substrate-Specificity. Proc. Natl. Acad. Sci. U. S. A 1991, 88 (11), 4690-4694. [PubMed: 2052552]

(9). Krokan HE; Drablos F; Slupphaug G Uracil in DNA - Occurrence, Consequences and Repair. Oncogene 2002, 21 (58), 8935-8948. [PubMed: 12483510]

(10). Dizdaroglu M Oxidatively Induced DNA Damage and Its Repair in Cancer. Mutat. Res., Rev. Mutat. Res 2015, 763, 212-245. [PubMed: 25795122]

(11). Al-Tassan N; Chmiel NH; Maynard J; Fleming N; Livingston AL; Williams GT; Hodges AK; Davies DR; David SS; Sampson JR; Cheadle JR Inherited Variants of MYH Associated with Somatic G C -> T A Mutations in Colorectal Tumors. Nat. Genet 2002, 30 (2), 227-232. [PubMed: 11818965]

(12). Liu C; Tu Y; Yuan J; Mao X; He S; Wang L; Fu G; Zong J; Zhang Y Aberrant Expression of NMethylpurine-DNA Glycosylase Influences Patient Survival in Malignant Gliomas. J. Biomed. Biotechnol 2012, 2012, 1. [PubMed: 21836813]

(13). Visnes T; Grube M; Hanna BMF; Benitez-Buelga C; Cazares-Körner A; Helleday T Targeting BER Enzymes in Cancer Therapy. DNA Repair 2018, 71, 118-126. [PubMed: 30228084]

(14). Visnes T; Cázares-Körner A; Hao W; Wallner O; Masuyer G; Loseva O; Mortusewicz O; Wiita E; Sarno A; Manoilov A; Astorga-Wells J; Jemth A-S; Pan L; Sanjiv K; Karsten S; Gokturk C; Grube M; Homan EJ; Hanna BMF; Paulin CBJ; Pham T; Rasti A; Berglund UW; von Nicolai C; Benitez-Buelga C; Koolmeister T; Ivanic D; Iliev P; Scobie M; Krokan HE; Baranczewski P; Artursson P; Altun M; Jensen AJ; Kalderén C; Ba X; Zubarev RA; Stenmark P; Boldogh I; Helleday T Small-Molecule Inhibitor of OGG1 Suppresses Proinflammatory Gene Expression and Inflammation. Science 2018, 362 (6416), 834-839. [PubMed: 30442810]

(15). He Y-F; Li B-Z; Li Z; Liu P; Wang Y; Tang Q; Ding J; Jia Y; Chen Z; Li L; Sun Y; Li X; Dai Q; Song C-X; Zhang K; He C; Xu G-L Tet-Mediated Formation of 5-Carboxylcytosine and Its Excision by TDG in Mammalian DNA. Science 2011, 333 (6047), 1303-1307. [PubMed: 21817016]

(16). Wilson DL; Kool ET Fluorescent Probes of DNA Repair. ACS Chem. Biol 2018, 13 (7), 17211733. [PubMed: 29156135]

(17). Lee CY; Park KS; Park HG Pyrrolo-DC Modified Duplex DNA as a Novel Probe for the Sensitive Assay of Base Excision Repair Enzyme Activity. Biosens. Bioelectron 2017, 98, 210214. [PubMed: 28683413]

(18). Yu W-T; Wu T-W; Huang C-L; Chen I-C; Tan K-T Protein Sensing in Living Cells by Molecular Rotor-Based Fluorescence-Switchable Chemical Probes. Chem. Sci 2016, 7 (1), 301-307. [PubMed: 28758005]

(19). Liu Y; Miao K; Dunham NP; Liu H; Fares M; Boal AK; Li X; Zhang X The Cation- $\pi$ Interaction Enables a Halo-Tag Fluorogenic Probe for Fast No-Wash Live Cell Imaging and Gel-Free Protein Quantification. Biochemistry 2017, 56 (11), 1585-1595. [PubMed: 28221782]

(20). Clark SA; Singh V; Vega Mendoza D; Margolin W; Kool ET Light-Up “Channel Dyes” for Haloalkane-Based Protein Labeling in Vitro and in Bacterial Cells. Bioconjugate Chem. 2016, 27 (12), 2839-2843.

(21). Kubo K; Ide H; Wallace SS; Kow YW A Novel Sensitive and Specific Assay for Abasic Sites, the Most Commonly Produced DNA Lesion. Biochemistry 1992, 31 (14), 3703-3708. [PubMed: 1567824]

(22). Bennett SE; Kitner J Characterization of the Aldehyde Reactive Probe Reaction with AP-Sites in DNA: Influence of AP-Lyase on Adduct Stability. Nucleosides, Nucleotides Nucleic Acids 2006, 25 (7), 823-842. [PubMed: 16898421] 
(23). Condie AG; Yan Y; Gerson SL; Wang Y A Fluorescent Probe to Measure DNA Damage and Repair. PLoS One 2015, 10 (8), No. e0131330.

(24). Boturyn D; Boudali A; Constant J-F; Defrancq E; Lhomme J Synthesis of Fluorescent Probes for the Detection of Abasic Sites in DNA. Tetrahedron 1997, 53 (15), 5485-5492.

(25). Carrasco MR; Alvarado CI; Dashner ST; Wong AJ; Wong MA Synthesis of Aminooxy and NAlkylaminooxy Amines for Use in Bioconjugation. J. Org. Chem 2010, 75 (16), 5757-5759. [PubMed: 20704452]

(26). Kölmel DK; Kool ET Oximes and Hydrazones in Bioconjugation: Mechanism and Catalysis. Chem. Rev 2017, 117 (15), 10358-10376. [PubMed: 28640998]

(27). Liu X; Qiao Q; Tian W; Liu W; Chen J; Lang MJ; Xu Z Aziridinyl Fluorophores Demonstrate Bright Fluorescence and Superior Photostability by Effectively Inhibiting Twisted Intramolecular Charge Transfer. J. Am. Chem. Soc 2016, 138 (22), 6960-6963. [PubMed: 27203847]

(28). Liu T-K; Hsieh P-Y; Zhuang Y-D; Hsia C-Y; Huang C-L; Lai H-P; Lin H-S; Chen I-C; Hsu H-Y; Tan K-T A Rapid SNAP-Tag Fluorogenic Probe Based on an Environment-Sensitive Fluorophore for No-Wash Live Cell Imaging. ACS Chem. Biol 2014, 9 (10), 2359-2365. [PubMed: 25105835]

(29). Kojima N; Takebayashi T; Mikami A; Ohtsuka E; Komatsu Y Construction of Highly Reactive Probes for Abasic Site Detection by Introduction of an Aromatic and a Guanidine Residue into an Aminooxy Group. J. Am. Chem. Soc 2009, 131 (37), 13208-13209. [PubMed: 19754181]

(30). Larsen D; Kietrys AM; Clark SA; Park HS; Ekebergh A; Kool ET Exceptionally Rapid Oxime and Hydrazone Formation Promoted by Catalytic Amine Buffers with Low Toxicity. Chem. Sci 2018, 9 (23), 5252-5259. [PubMed: 29997880]

(31). Wilson JN; Cho Y; Tan S; Cuppoletti A; Kool ET Quenching of Fluorescent Nucleobases by Neighboring DNA: The "Insulator" Concept. ChemBioChem 2008, 9 (2), 279-285. [PubMed: 18072185]

(32). Guckian KM; Schweitzer BA; Ren RX-F; Sheils CJ; Tahmassebi DC; Kool ET Factors Contributing to Aromatic Stacking in Water: Evaluation in the Context of DNA. J. Am. Chem. Soc 2000, 122 (10), 2213-2222. [PubMed: 20865137]

(33). Zhu A; Romero R; Petty HR A Sensitive Fluorimetric Assay for Pyruvate. Anal. Biochem 2010, 396 (1), 146-151. [PubMed: 19748474]

(34). McClure WR Kinetic Analysis of Coupled Enzyme Assays. Biochemistry 1969, 8 (7), $2782-$ 2786. [PubMed: 4241273]

(35). Taverna P; Liu L; Hwang H-S; Hanson AJ; Kinsella TJ; Gerson SL Methoxyamine Potentiates DNA Single Strand Breaks and Double Strand Breaks Induced by Temozolomide in Colon Cancer Cells. Mutat. Res., DNA Repair 2001, 485 (4), 269-281. [PubMed: 11585361]

(36). Dalhus B; Forsbring M; Helle IH; Vik ES; Forstrøm RJ; Backe PH; Alseth I; Bjørås M Separation-of-Function Mutants Unravel the Dual-Reaction Mode of Human 8-Oxoguanine DNA Glycosylase. Structure 2011, 19 (1), 117-127. [PubMed: 21220122]

(37). Marenstein DR; Chan MK; Altamirano A; Basu AK; Boorstein RJ; Cunningham RP; Teebor GW Substrate Specificity of Human Endonuclease III (HNTH1) Effect of Human APE1 on HNTH1 Activity. J. Biol. Chem 2003, 278 (11), 9005-9012. [PubMed: 12519758]

(38). Mol CD; Arvai AS; Sanderson RJ; Slupphaug G; Kavli B; Krokan HE; Mosbaugh DW; Tainer JA Crystal Structure of Human Uracil-DNA Glycosylase in Complex with a Protein Inhibitor: Protein Mimicry of DNA. Cell 1995, 82 (5), 701-708. [PubMed: 7671300]

(39). Bennett SE; Mosbaugh DW Characterization of the Escherichia Coli Uracil-DNA Glycosylase. Inhibitor Protein Complex. J. Biol. Chem 1992, 267 (31), 22512-22521. [PubMed: 1429601]

(40). Jollès B; Réfrégiers M; Laigle A Opening of the Extraordinarily Stable Mini-Hairpin d(GCGAAGC). Nucleic Acids Res. 1997, 25 (22), 4608-4613. [PubMed: 9358172]

(41). Haug T; Skorpen F; Aas PA; Malm V; Skjelbred C; Krokan HE Regulation of Expression of Nuclear and Mitochondrial Forms of Human Uracil-DNA Glycosylase. Nucleic Acids Res. 1998, 26 (6), 1449-1457. [PubMed: 9490791]

(42). Schermerhorn KM; Delaney S A Chemical and Kinetic Perspective on Base Excision Repair of DNA. Acc. Chem. Res 2014, 47 (4), 1238-1246. [PubMed: 24646203] 
(43). Chen C; Zhou D; Tang H; Liang M; Jiang J A Sensitive, Homogeneous Fluorescence Assay for Detection of Thymine DNA Glycosylase Activity Based on Exonuclease-Mediated Amplification. Chem. Commun 2013, 49 (52), 5874-5876.

(44). Edwards SK; Ono T; Wang S; Jiang W; Franzini RM; Jung JW; Chan KM; Kool ET In Vitro Fluorogenic Real-Time Assay of the Repair of Oxidative DNA Damage. ChemBioChem 2015, 16 (11), 1637-1646. [PubMed: 26073452]

(45). Tahara Y; Auld D; Ji D; Beharry AA; Kietrys AM; Wilson DL; Jimenez M; King D; Nguyen Z; Kool ET Potent and Selective Inhibitors of 8-Oxoguanine DNA Glycosylase. J. Am. Chem. Soc 2018, 140 (6), 2105-2114. [PubMed: 29376367]

(46). Lindahl T; Nyberg B Rate of Depurination of Native Deoxyribonucleic Acid. Biochemistry 1972, 11 (19), 3610-3618. [PubMed: 4626532]

(47). Klungland A; Lindahl T Second Pathway for Completion of Human DNA Base Excision-Repair: Reconstitution with Purified Proteins and Requirement for DNase IV (FEN1). EMBO J. 1997, 16 (11), 3341-3348. [PubMed: 9214649]

(48). Liu B; Yang X; Wang K; Tan W; Li H; Tang H Real-Time Monitoring of Uracil Removal by Uracil-DNA Glycosylase Using Fluorescent Resonance Energy Transfer Probes. Anal. Biochem 2007, 366 (2), 237-243. [PubMed: 17553452] 


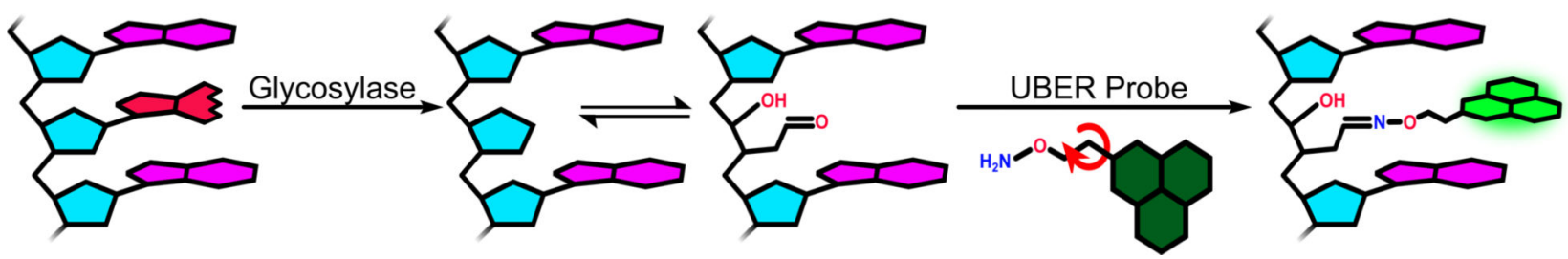

Figure 1.

Light-up mechanism of the UBER probe design in measuring DNA glycosylase activity. Upon excision of a damaged DNA base by the glycosylase of interest, the resulting hemiacetal form of the DNA AP site reacts with the aminooxy linker of the UBER probe to yield a strongly fluorescent probe-DNA oxime conjugate. Prior to oxime formation with the DNA AP site, the UBER probe is largely nonfluorescent due to free bond rotation about the linker attachment site. The neighboring bases of the DNA duplex constrain bond rotation, yielding a fluorescence response that is highly specific for the AP site of DNA over smallmolecule aldehydes and ketones. 
a)
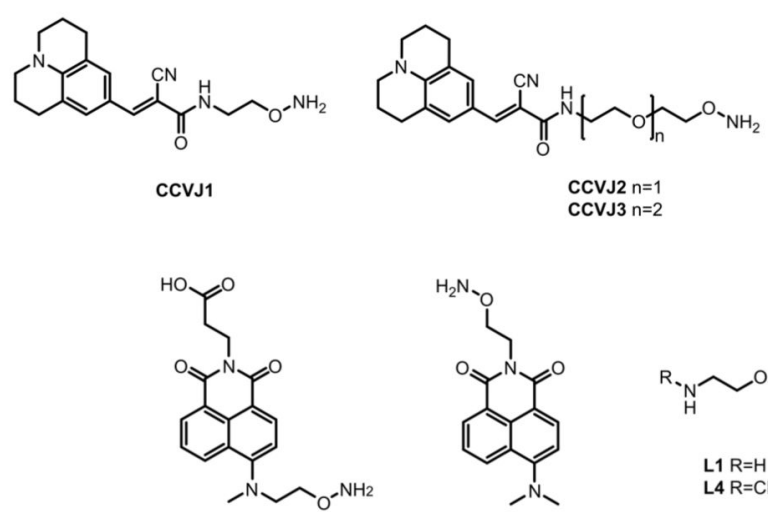

NP1

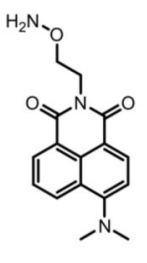

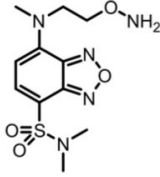

BD1

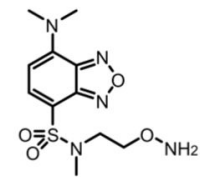

BD2

b)
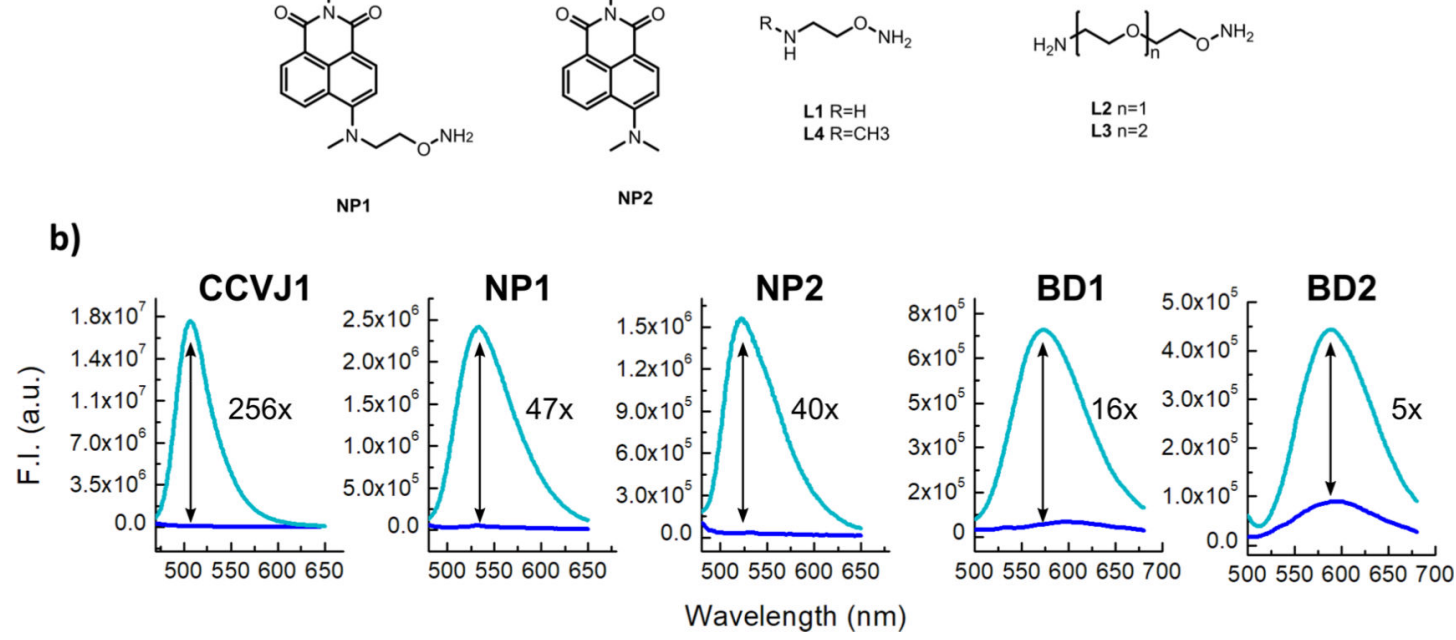

Figure 2.

Probes and their properties. (a) Structures of the UBER probes and aminooxy linkers reported in this study. (b) Emission spectra of oligonucleotide-probe conjugates compared to the emission spectra of the free probe at $2 \mu \mathrm{M}$ concentration in $50 \mathrm{mM}$ Tris buffer $\mathrm{pH}$ 7.0. Excitation was at $470 \mathrm{~nm}$ for CCVJ1 and $450 \mathrm{~nm}$ for NP1/2 and BD1/2. 

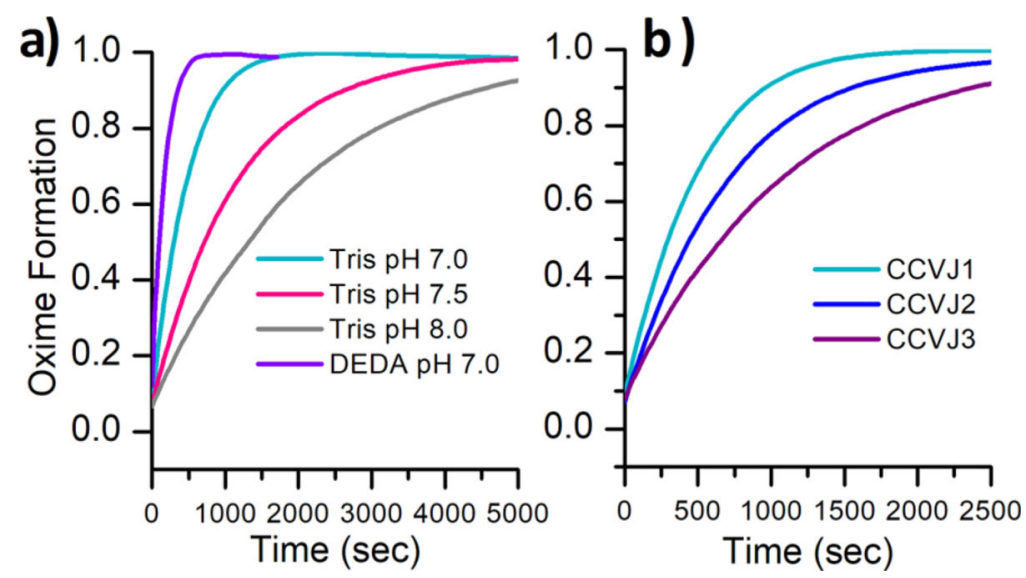

Figure 3.

Fluorescence real-time responses with varied conditions and dye linkers. (a) Time course of oxime formation between CCVJ1 $(5 \mu \mathrm{M})$ and AP-DNA $(20 \mu \mathrm{M})$ under varied buffer conditions $(50 \mathrm{mM})$. Ionic strength adjusted to $150 \mathrm{mM}$ with $\mathrm{NaCl}$. (b) Time course of CCVJ1-3 $(5 \mu \mathrm{M})$ with AP-DNA $(20 \mu \mathrm{M})$ in $50 \mathrm{mM}$ Tris pH 7.0 buffer. Ionic strength adjusted to $150 \mathrm{mM}$ with $\mathrm{NaCl}$. 

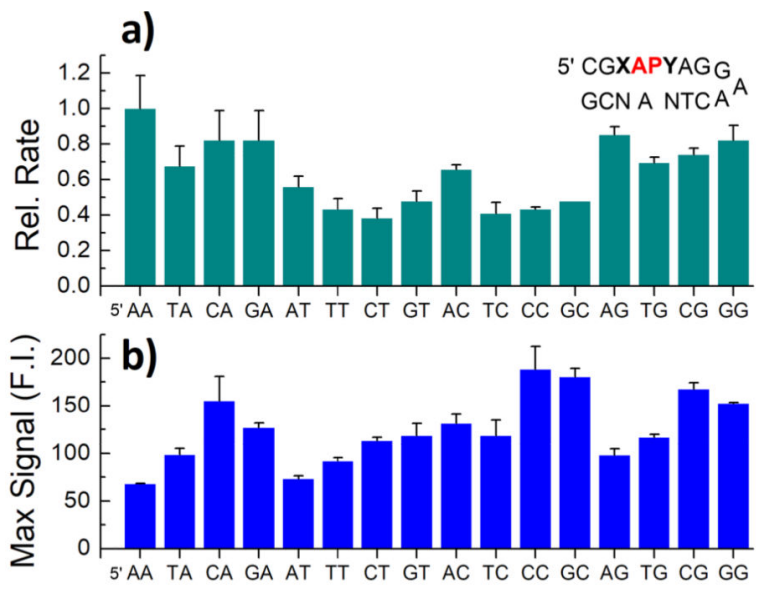

c)

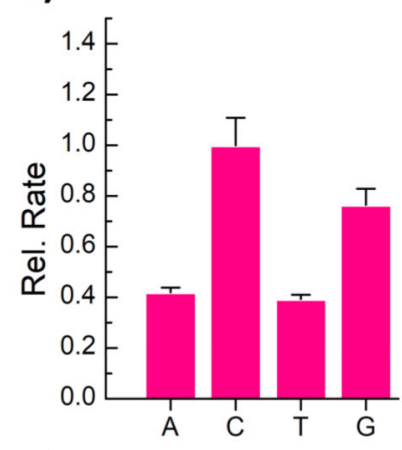

d)
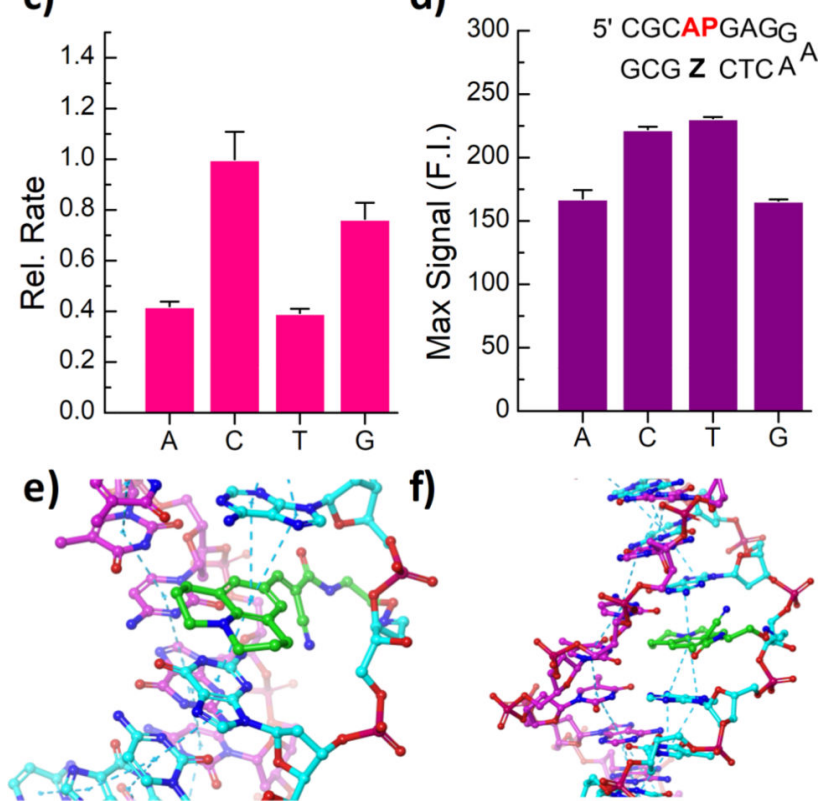

Figure 4.

Effects of structural context on CCVJ1 probe. (a, b) Base identities of $\mathbf{X}$ and $\mathbf{Y}$ are listed on $X$-axis as neighboring pairs XY. (c, d) Base identity of $\mathbf{Z}$ is listed on $X$-axis. (a, c) Relative reaction rates between CCVJ1 $(5 \mu \mathrm{M})$ and AP-DNA $(20 \mu \mathrm{M})$ with varied (a) neighboring bases or (c) opposing bases. (b, d) Maximum fluorescence signal observed between CCVJ1 $(5 \mu \mathrm{M})$ and AP-DNA ( $20 \mu \mathrm{M})$ with varied (b) neighboring bases or (d) opposing bases. All values based on average of duplicate runs. (e, f) Model of CCVJ1 (green) covalently bound to the AP-site of DNA viewed from (e) major groove and (f) minor groove. 


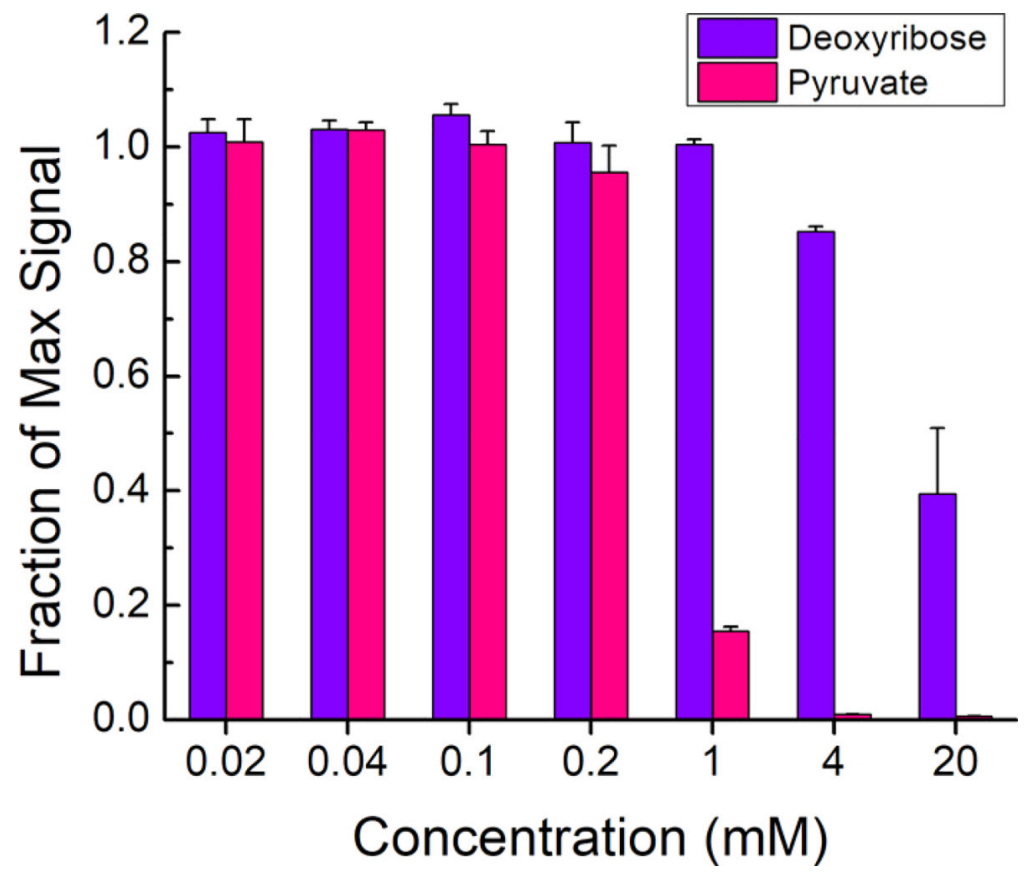

Figure 5.

Effect of competing aldehydes/ketones on maximum fluorescence signal. CCVJ1 (5 $\mu \mathrm{M})$ was reacted with AP DNA $(20 \mu \mathrm{M})$ in the presence of increasing amounts of deoxyribose or pyruvate. Maximum fluorescence values were observed after $1 \mathrm{~h}$ and compared to the control with no competing aldehyde/ketone. 

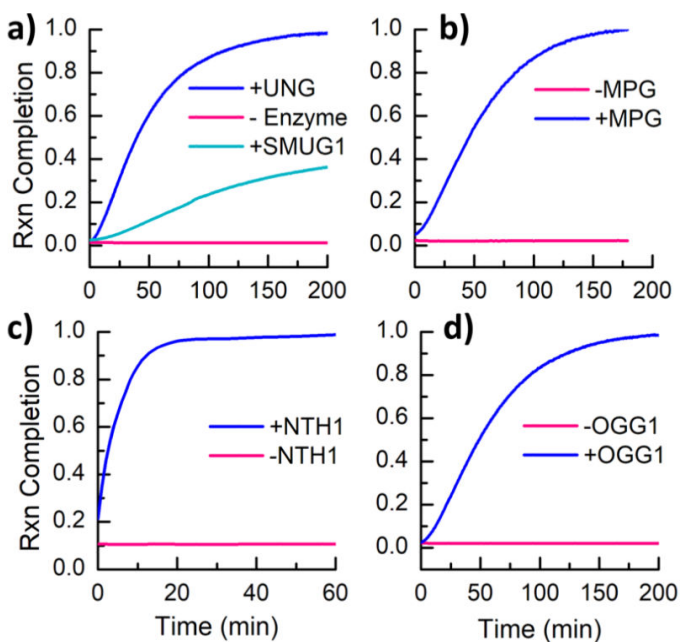

e)
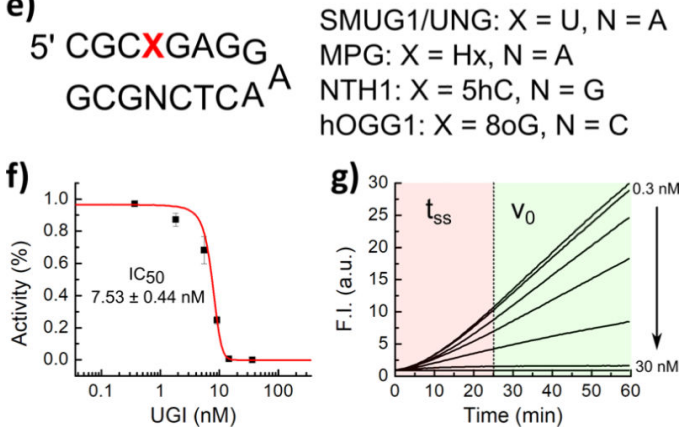

Figure 6.

Quantitative coupled assays using CCVJ1. Shown are data from reaction of lesion containing substrates with (a) UNG and SMUG1 (5 nM), (b) MPG (100 nM), (c) NTH1 $(500 \mathrm{nM}),(\mathrm{d})$ OGG1 $(100 \mathrm{nM})$ in real-time with $(\mathrm{a}, \mathrm{b}, \mathrm{d})$ lesion-containing DNA $(2 \mu \mathrm{M})$ and CCVJ1 $(20 \mu \mathrm{M})$ or (c) lesion-containing DNA $(60 \mu \mathrm{M})$ and CCVJ1 $(20 \mu \mathrm{M})$. (e) Sequences of lesion-containing hairpin substrates. (f) $\mathrm{IC}_{50}$ curve of UGI with UNG fitted to the Boltzmann equation. (g) Real-time fluorescence traces of UNG with increasing concentrations of UGI ( 0.3 to $30 \mathrm{nM})$. Delay time $t_{\mathrm{ss}}$ of 25 min indicated with dotted line. 


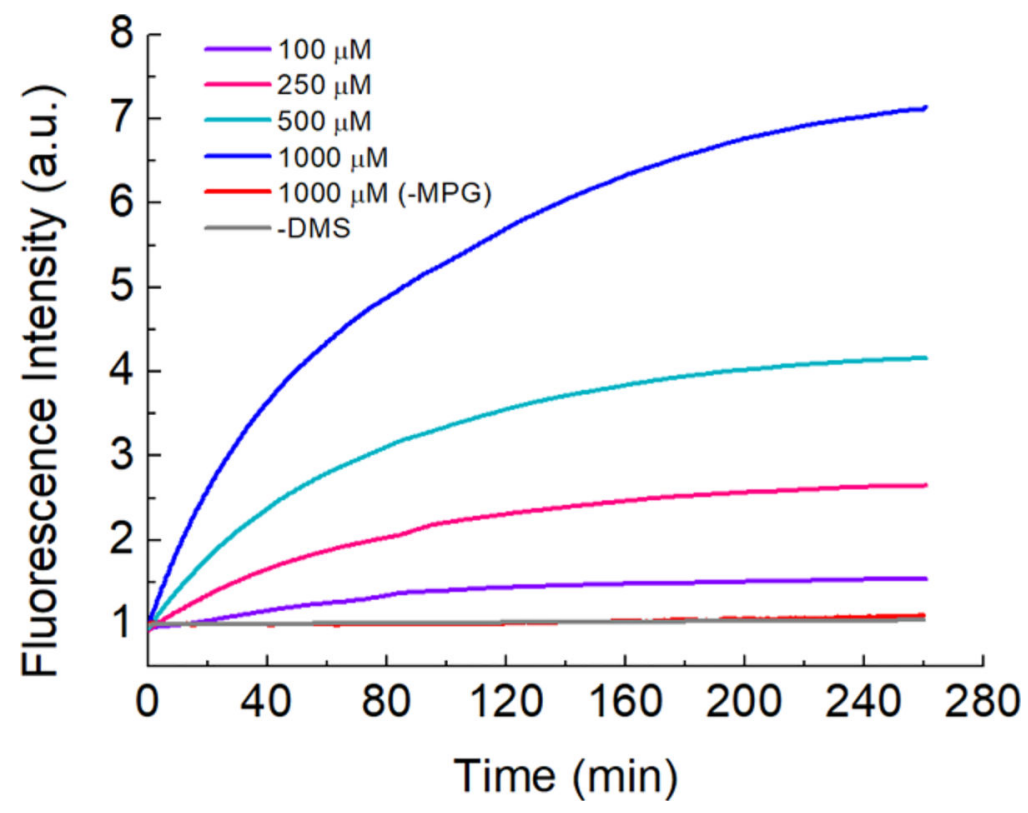

Figure 7.

Measuring real-time MPG-mediated base excision of alkylated bases in calf thymus DNA $(0.1 \mathrm{mg} / \mathrm{mL})$ by $100 \mathrm{nM}$ MPG enzyme in the presence of CCVJ1 $(20 \mu \mathrm{M})$. The results with different concentrations of alkylating agent are shown. 

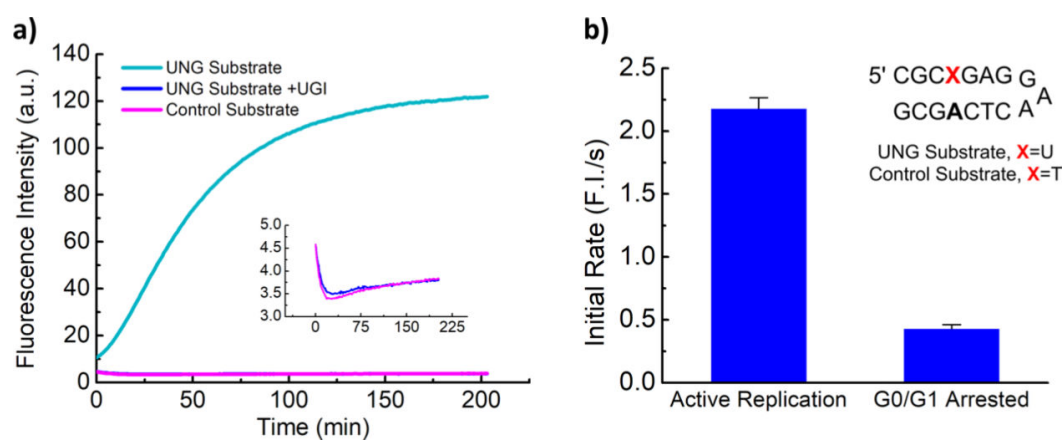

Figure 8.

Applications of an UBER probe for measuring multiple repair activities in cell lysates. (a) Fluorescence time-course of $25 \mu \mathrm{M}$ CCVJ1 with HeLa cell lysate $(0.2 \mathrm{mg} / \mathrm{mL})$ and $5 \mu \mathrm{M}$ of UNG hairpin substrate. The inhibitor UGI was used at a concentration of $1 \mathrm{U} / \mathrm{mL}$ to completely abolish UNG activity. Inset shows close overlap of the control and UGI treated lysates. (b) Quantification of UNG activity in actively replicating HeLa cells and G0/G1 cell cycle arrested HeLa cells. Activity was quantified by measuring initial rate velocity using 25 $\mu \mathrm{M}$ CCVJ1 with lysate $(0.2 \mathrm{mg} / \mathrm{mL})$ and $5 \mu \mathrm{M}$ of UNG hairpin substrate. 


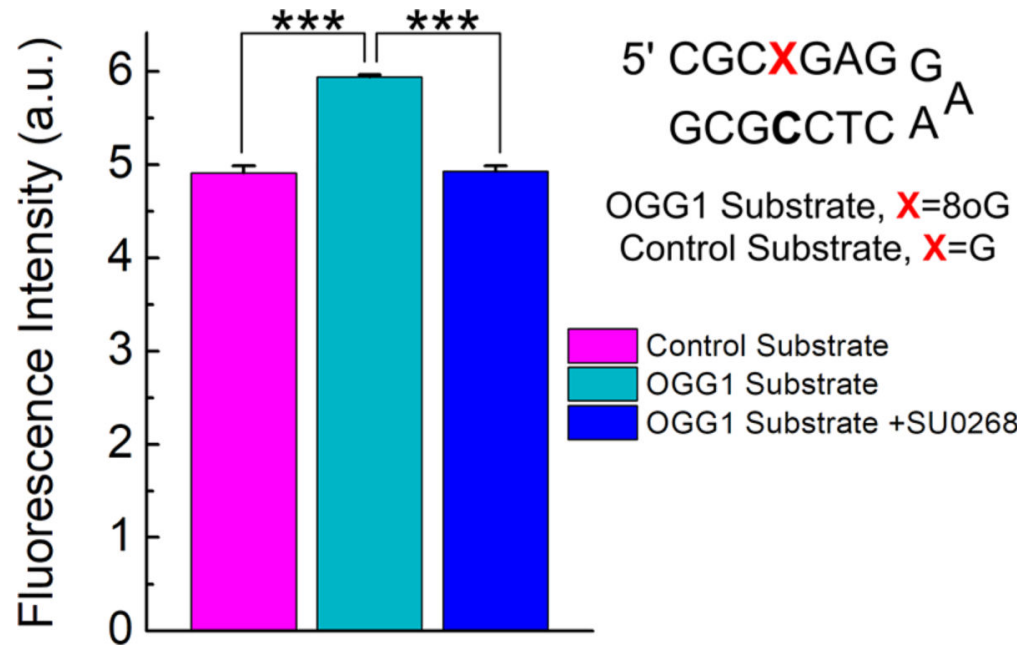

Figure 9.

Fluorescence measurement of MCF7 cell lysates $(0.2 \mathrm{mg} / \mathrm{mL})$ with $25 \mu \mathrm{M}$ CCVJ1 following a 4-h incubation with $5 \mu \mathrm{M}$ of an OGG1 hairpin substrate. The inhibitor SU0268 was used to abrogate OGG1 activity. Error bars represent standard deviation of three replicates. 
Table 1.

Apparent Second-Order Rate Constants of Oxime Formation between CCVJ1 and AP-DNA ${ }^{a}$

\begin{tabular}{lc}
\hline \multicolumn{1}{c}{ buffer } & $\boldsymbol{k}_{\mathbf{2}}\left(\mathbf{M}^{\mathbf{- 1}} \mathbf{s}^{\mathbf{- 1}}\right)$ \\
Tris pH 7 & $147 \pm 8$ \\
Tris pH 7.5 & $51 \pm 2$ \\
Tris pH 8 & $29 \pm 1$ \\
DEDA pH 7 & $440 \pm 12$ \\
\hline
\end{tabular}

${ }^{a}$ Buffer concentration $50 \mathrm{mM}$ and ionic strength adjusted to $150 \mathrm{mM}$ with $\mathrm{NaCl}$. Values represent average of three independent replicates, with standard deviations shown. 